\title{
When more is less in financial decision-making: financial literacy magnifies framing effects
}

\author{
Vânia Moreira Costa ${ }^{1}$ (1) $\cdot$ Nuno A. De Sá Teixeira ${ }^{2} \cdot$ Ana Cordeiro Santos $^{3} \cdot$ Eduardo Santos $^{1}$
}

Received: 11 December 2019 / Accepted: 11 June 2020

○) Springer-Verlag GmbH Germany, part of Springer Nature 2020

\begin{abstract}
In recent years, the financial world has become more complex and intricate. In this context, numeracy and, particularly, financial literacy, are seen as paramount in providing consumers with the knowledge and confidence required to take part in financial markets. Despite some indicative empirical findings, it is still to be ascertained how the two competences differentially contribute to the quality of decision-making in financial contexts. Furthermore, it is still unknown to what degree financial literacy and numeracy, taken as relevant mind-ware for financial decision-making, are effective in guarding against well-documented biases such as loss aversion and framing effects. This study aims to clarify these issues by employing an experimental task, conceived as an approximation to real-world decision-making involving the sale of shares. Our results suggest that numeracy and financial literacy affect decision-making differently in a pattern that, in part, runs counter to conventional economic theory. The data indicate that numeracy promotes a pattern of choices closer to economic rationality, while financial literacy can prove counterproductive and may amplify cognitive biases, namely framing effects and loss aversion. The outcomes are interpreted in light of dual-process theories, and the political implications discussed.
\end{abstract}

\section{Introduction}

As a result of more systemic transformations in contemporary societies, individuals and households find themselves increasingly engaged in financial decision-making — whether to finance basic consumer goods or more fundamental needs, such as education, healthcare, housing or retirement (Santos, 2017). Over the last three to four decades, we have been witnessing the rise of household debt promoted by the twofold effect of depressed economies and the growth of credit facilitated by financial innovation making it increasingly available to low-income households (e.g., through securitisation of mortgage debt and the originate-and-distribute strategies of commercial banks; Crotty, 2009). On the other hand, the decline of welfare states, specifically in the area of health

Vânia Moreira Costa

vania.moreira.costa@gmail.com

1 Institute of Cognitive Psychology, Human and Social Development, University of Coimbra, Rua Do Colégio Novo, 3000-115 Coimbra, Portugal

2 Department of Education and Psychology, William James Research Centre, University of Aveiro, Aveiro, Portugal

3 Centre for Social Studies, University of Coimbra, Coimbra, Portugal and retirement, has meant that individuals increasingly have had to take responsibility for their future financial well-being through the contracting of health insurance and enrolment in pension funds.

Financial literacy has thus become a highly relevant skill not only because individuals now live in a world where they have to make more decisions of this kind, but also because they seem to be extraordinarily ill-prepared for them. Successive international surveys have highlighted these concerns (Lusardi \& Mitchell, 2014; OECD, 2005; OECD/ INFE, 2016; Standard \& Poor's, 2015). The first international study sponsored by the OECD, in 2005, showed that relevant segments of the population in the developed world do not have the necessary knowledge or understanding to cope with basic financial decisions. In Australia, 51\% of respondents were unable to correctly interpret a simple hypothetical bank statement, and while $67 \%$ stated they understood the concept of compound interest, only $28 \%$ succeeded in solving a problem requiring the use of the concept. Similar findings were unearthed in the UK and the USA, with respondents claiming to know more than what could be inferred from their performances in basic tests. These results have been subsequently replicated. In one recent survey (OECD, 2017), only a small percentage of respondents (27\%) were able to calculate a simple interest on a deposit 
and successfully recognise that the value of interest compounded over 5 years would be greater than five times the simple interest.

Alarmed by both present-day and future harmful individual and collective consequences of poor financial decisions, as exposed by the global financial crisis (GFC), governments all over the world have implemented financial education initiatives (OECD, 2009; OECD \& INFE, 2014). The growing political relevance and visibility of financial literacy have inspired a research agenda devoted to the study of the impact of financial literacy on individual behaviour. A significant part of that work has sought to show that financially literate individuals display different and improved patterns of behaviour in comparison with individuals with lower scores on financial literacy tests. For example, it was shown that consumers with higher scores of financial literacy are more likely to invest in the stock market (Jappelli \& Padula, 2013; van Rooij, Lusardi \& Alessie, 2011), to accumulate savings (de Bassa Scheresberg, 2013) or to enrol in retirement savings plans (Lusardi \& Mitchell, 2007a, 2014). By the same token, lower scores of financial literacy have been found to be related to detrimental financial behaviour, such as high levels of indebtedness, low savings, inadequate retirement planning, and onerous credit options (Moore, 2003; Disney \& Gathergood, 2013; Lusardi \& Mitchell, 2007a, b).

However, there is no agreement on the efficacy of financial education initiatives (O'Connel, 2008). Based on a meta-analysis covering 201 studies, Fernandes et al. (2014) concluded that interventions to improve financial literacy account for no more than $0.1 \%$ variance in financial behaviour. In an attempt to address this surprising result, a recent study (Skagerlund, Lind, Strömbäck, Tinghög \& Västfäll, 2018) sought to identify the presence of other cognitive and emotional factors that could interfere with the attainment of financial literacy and which might explain the lack of efficacy of financial education. Based on a survey conducted in a representative sample of Swedish adults, the authors concluded that 'a driving force behind becoming financially literate resides in the ability to understand numbers and having an emotional attitude towards numbers that does not interfere with an individual's daily engagement in activities involving mathematics and financial decisions' (p. 24). They argue that numeracy, defined as the ability to process basic numerical concepts, quantitative estimations, probability and ratios, is required to solve financial problems. Hence, numeracy provides 'the computational engine behind financial decision making' (p. 19). This may well explain the failure of financial education insofar as knowledge of financial concepts, such as inflation and risk diversification, require basic calculations, such as obtaining percentages and probabilities.

Simultaneously, it has been found that numeracy is associated with significantly improved performance in judgment and decision-making tasks. For instance, numeracy has been shown to be a relevant skill in decision-making relating to risk and uncertainty, a distinctive feature of several financial decisions (Cokely \& Kelley, 2009; Lusardi, 2012; Peters et al., 2006; Peters \& Levin, 2008; Zokaityte, 2016). But numeracy levels have also been found to be low among the population as a whole, even among individuals with higher academic qualifications (Kirsch et al., 2002; Lipkus et al., 2001; Reyna \& Brainerd, 2008; Sutherland, 1992).

Notwithstanding, research on numeracy and financial literacy has, for the most part, been kept apart, treated as separate entities evolving in parallel, with few studies exploring their joint role in determining decision-making capabilities. Furthermore, and taking both numeracy and financial literacy as expert knowledge, it is worth exploring their role in light of recent advances in psychology, which will be briefly reviewed in the next subsection.

\section{Dual-process theory, financial literacy and numeracy}

According to dual-process theories, human cognitive activities, including decision-making, involve the interplay of intuitive and analytical cognitive processes, usually referred to as type 1 and type 2 processes, respectively (Evans \& Stanovich, 2013; Kahneman, 2003; Kahneman \& Frederick, 2002; Stanovich \& West, 1999, 2000). For the most part, human reasoning and behaviour are controlled by Type 1 intuitive processes, with a high degree of automatic and effortless information processing, favouring the generation of fast responses with little use of attentional resources. However, and due to their heuristic nature, type 1 responses are not guaranteed to be accurate and, in fact, are often at odds with normative standards (e.g., expected utility theory-EUT), leading to decision errors and biases (Evans \& Stanovich, 2013; Kahneman, 2011; Stanovich, West \& Toplak, 2016). For example, it has been found that the way in which a given decision-making problem is presented (framed) has an effect on the choices made, implying that an individual can provide different responses to the exact same problem, dubbed in the literature as 'framing effects' (Tversky \& Kahneman, 1981, 1986). The latter stand as a violation of the principle of invariance, a key axiom of EUT that posits the neutrality of elicitation procedures, implying that a rational agent would choose the option that maximises the expected value, irrespective of how it is formulated. Contrarily, human decision-makers often make disparate choices when the problem is formulated in terms of gains or, alternatively, losses (Tversky \& Kahneman, 1981, 1984). Within the logic of the Prospect Theory (Kahneman \& Tversky, 1979), these trends can be accounted for by positing that humans are sensitive to changes in wealth, in respect to a current reference point, rather than to overall wealth. That 
is, the ultimate carriers of utility are wealth changes, not final states. Moreover, people place greater value on losses than on comparable nominal gains, being more prone to seek risk to avoid a certain loss, but risk averse for possible gains. This reflection has been referred to as 'loss aversion' (cf. Kahneman \& Tversky, 1979) and has been reported in consumer, health, and economic decision-making processes (Diacon \& Hasseldine, 2007; Epley, Mak, Idson, 2006; McNeil, Pauker, Sox, \& Tversky, 1982; Sanford, Fay, Stewart, \& Moxey, 2002). Further evidence has suggested that framing effects and, by extension, loss aversion, are part of an affective type 1 heuristic process (Cassotti et al., 2012; Kahneman \& Frederick, 2007). Corroborating this premise, De Martino, Kumaran, Seymour, and Dolan, (2006) found that framing effects seem to be related to the activation of emotional neuronal substrates, such as the amygdala, whereas more rational answers, demonstrating less susceptibility biases, were correlated with an increased activity in the orbital and medial prefrontal cortex.

Of course, deviations to a normative correct response, such as those brought about by framing effects, can be circumvented through careful reflective analysis of the problem (type 2 responses), albeit at a significant cost in terms of effort and attentional resources, and provided that an intuitive type 1 response is blocked (Evans, 2003, 2010; Kahneman, 2011). Due to its deliberative nature, type 2 responses might yield a normatively correct response if the responder possesses relevant knowledge and expertise, i.e., adequate 'mindware' (Stanovich, West, \& Toplak, 2011, Stanovich et al., 2016). As such, type 2 processes do not necessarily generate the normatively correct response, particularly when the individual lacks adequate expertise.

The link between the basic features of dual-process theories and the literature on numeracy and financial literacy in financial decision-making is straightforward: more numerate and financially-literate individuals, to the extent that they possess the relevant mindware, are more likely to employ strategies and processes which generate normatively superior, type 2, responses in financial contexts, as long as no cognitive restrictions are imposed on them (e.g., no time constraints and no working memory load). Accordingly, various studies have been implemented to test whether more numerate individuals conform to the normative predictions when presented with problems designed around choices between a sure and a risky option. It has been found that higher numeracy leads to more choices in line with the maximization of the expected value of a lottery and, hence, less prone to framing effects or the influence of irrelevant information (Peters et al., 2006; Peters, Slovic, Västfjäll, \& Mertz, 2008). A possible interpretation is that numeracy, by promoting the processing of numerical information, favours the correct calculation of the expected value (Garcia-Retamero, Sobkow, Petrova, Garrido \& Traczyk, 2019).
To the best of our knowledge, studies examining the effects of financial literacy on decision-making problems involving risk is yet to be carried out. While financial literacy requires a firm grasp of numbers, percentages, and calculation procedures, as with numeracy, it also involves knowledge of financial concepts such as compounded interest, inflation and risk diversification, not covered by numeracy. This study thus aims to clarify to what extent financial literacy impacts on decision-making beyond what could be accounted for by numeracy.

\section{The present study}

As outlined thus far with respect to financial decisionmaking, both financial literacy and numeracy are arguably prime candidates for relevant mindware. Individuals with high levels of financial literacy and numeracy would thus be expected to outperform their less sophisticated counterparts and, hence, to be less prone, or more immune, to loss aversion and framing effects. This study aims primarily to ascertain to what degree this is the case. As such, we adapted the task used by De Martino et al. (2006), with a sure option pitched against a gamble option in hypothetical scenarios involving shared values. The task was devised to allow the simultaneous assessment of loss aversion and framing effects (by systematically varying the formulation of the sure option by specifying the amounts of financial shares as either retained or lost) as well as the degree to which participants tend to choose the options with the higher expected values in accordance with EUT (by systematically varying the value of the sure option such that it could be higher, lower or equal to the expected value of the accompanying gamble $)^{1}$. It was hypothesized that participants with higher levels of financial literacy and numeracy (measured using appropriate questionnaires responded to after completing the experimental task) would: (1) display a pattern of responses closely in line with the theoretical prediction (that is, choosing the alternative implying a higher payoff), and (2) be less susceptible to framing effects (that is, with the choice for the gamble option being less affected by the formulation of the sure option as a gain or a loss). Furthermore, the design of this study also allows assessing the relative contributions of financial literacy and numeracy in reaching (or deviating from) the normative predictions as well as

\footnotetext{
${ }_{1}^{1}$ In the present paper, we will take maximization of the excepted value as the normatively correct strategy, mostly due to its straightforward calculation and interpretation. For the most part, our conclusions would be unchanged if Expected Utility was considered instead (with the added issue that a utility function would have to be assumed), as the latter should be a monotonously increasing function of the former (Von Neumann \& Morgenstern, 1947).
} 
Fig. 1 Sequence of events in each trial

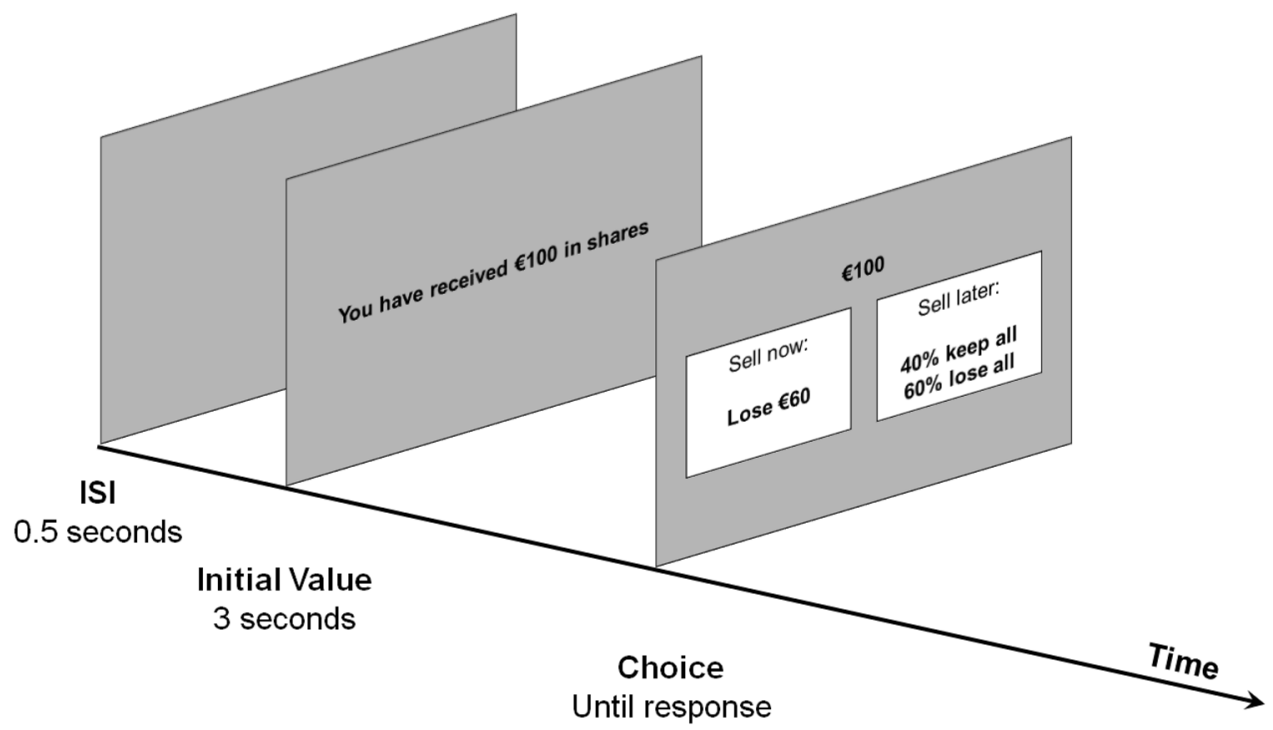

their interrelationship (e.g., independent, additive effects or mutual interactive magnification).

\section{Method}

\section{Participants}

One hundred adult participants (61 females; 39 males), aged between 23 and 68 years, $(M=35.28$; $\mathrm{DP}=8.193)$, with above-average or high-level qualifications (61\% holding a masters and/or a Ph.D. and $31 \%$ with a bachelor's degree) volunteered for the experiment. All the participants were unaware of the purpose of the study and had provided informed consent. The experimental protocol was approved by the Ethics Committee of the University of Coimbra.

\section{Materials}

A set of hypothetical scenarios involving a financial choice was used as the stimulus. The scenarios presented an initial value for a set of shares in an electrical company that, due to fluctuations in the market, would depreciate in value. The scenarios offered two options-either to sell the shares immediately at their current value (hereafter referred to as either the sure or the sell option) or sell the shares later with a specified probability of retaining or losing the entire initial amount (henceforth referred to as the gamble option). The initial value of the shares ranged from $€ 100$ to $€ 200$ in increments of $€ 20$ (amounting to six possible initial values). As for the gamble option, the probability of retaining the initial value ranged from 20 to $80 \%$ (with the probability of losing the initial value provided by the complementary percentages), at intervals of $20 \%$ (thereby totalling four possible probabilities). The values of the sure option $\left(V_{\text {sell }}\right)$ were calculated based on the expected value of the gamble option $\left(\mathrm{EV}_{\text {gamble }}\right)$ with which it was paired for each combination of initial value and the probability of retaining the total amount: for each trial, the shares could be sold at either the nominal expected value for the gamble option (i.e., $V_{\text {sell }}=\mathrm{EV}_{\text {gamble }}$ ), at a value 0.2 times higher (i.e., $V_{\text {sell }}=\mathrm{EV}_{\text {gamble }}+0.2 \times \mathrm{EV}_{\text {gamble }}$ ) or 0.2 times lower (i.e., $\left.V_{\text {sell }}=\mathrm{EV}_{\text {gamble }}-0.2 \times \mathrm{EV}_{\text {gamble }}\right)$. Furthermore, each sure option could be presented in terms of retained or lost value (framed as 'keep $X €$ ' or 'lose $X €$ '). Prior to the experimental task, all participants performed a series of practice trials, in all respects similar to the experimental task but with different initial values (ranging from $€ 20$ to $€ 80$ ). For each trial, the initial value of the shares was presented in the centre of a computer screen for $3 \mathrm{~s}$ (e.g., 'you have received $120 €$ in shares'). Immediately afterwards, the two choices [sure option ('sell now') and gamble option ('sell later')] were presented side by side within two white boxes (see Fig. 1) on an otherwise neutral grey background. The position of each option (right or left box) was randomised in each trial. The initial value of the shares was always displayed above the two options, for reference. Stimuli presentation, trial randomisation and collection of responses were programmed using PsychoPy (Peirce, 2007, 2009) and the scenarios presented on an 11.6' inch screen (with a resolution of $1366 \times 768$ pixels and a $60 \mathrm{~Hz}$ refresh rate).

After completion of the experimental task, numeracy and financial literacy levels were assessed for all participants by employing the Abbreviated Numeracy Scale (Weller et al., 2013; translated to Portuguese by the authors of this study) and the Financial Literacy Questionnaire (Bank of Portugal, 2015), respectively. The Abbreviated Numeracy Scale consists of eight open-ended questions, six of which are devised 
to assess the understanding of probabilities and percentages while the remaining two are adapted from the Cognitive Reflection Test (Frederick, 2005) with the intention of triggering intuitive but normatively erroneous answers, thus measuring to what extent the respondent is able to inhibit type 1 responses and replace them with type 2 versions. The scores for the Abbreviated Numeracy Scale are provided by the number of correct answers (up to a maximum of eight) and has been found to be a unidimensional measure of numeracy conforming closely to a normal distribution (Weller et al., 2013). For the present sample, Cronbach's Alpha for the Abbreviated Numeracy Scale was found to be 0.73 .

The Financial Literacy Questionnaire was devised by the Bank of Portugal (2015) in accordance with OECD guidelines and includes questions about financial attitudes, behaviour and knowledge. For this study, only the set of questions related to financial knowledge were used (for similar procedures see Lusardi \& Mitchell, 2007, Lusardi \& Mitchell, 2007, 2011, 2014; Skagerlund et al., 2018). This section is composed of 30 questions (both open-ended and multiple choice) aimed at assessing the respondents' understanding of inflation, simple interest rate, compound interest rate, diversification, risk/benefit balance, characteristics of the most common banking products, such as current and deposit accounts, credit card costs and loan interest rates, as well as concepts related to insurance and investment products. The number of correct responses (up to a maximum of 30) was taken as a measure of financial literacy and the value of Cronbach's Alpha was found to be 0.8 .

\section{Procedure and design}

Participants sat at about $60 \mathrm{~cm}$ from the screen without head constraints but asked to keep an upright posture. Written instructions for the experimental task were presented on the screen prior to the practice trials and the subsequent set of experimental trials. For each scenario, participants were instructed to select their preferred option (sure or gamble) by pressing either the ' $\mathrm{z}$ ' or the ' $\mathrm{m}$ ' key on a QWERTY keyboard to indicate the choice of alternatives displayed in the left of the right box, respectively. The trial was completed as soon as a response was provided, and a new trial was initiated after an inter-stimulus interval of $0.5 \mathrm{~s}$. After completion of the task, participants answered the items contained in the Abbreviated Numeracy Scale and the Financial Literacy Questionnaire and were debriefed. The experiment conformed to a factorial repeated-measures design given by 6 (initial value: $100 €, 120 €, 140 €, 160 €, 180 €$ or $200 €) \times 4$ (win probability for the gamble option: $80 \%, 60 \%, 40 \%$ or $20 \%) \times 3$ (value difference between the sure option and expected value of the gamble, $+0.2,0$ or -0.2$) \times 2$ (framing of the sure option: 'keep'/'lose'), thus totalling 144 trials.
Each session, including instructions, experimental task, responses to the questionnaires and debriefing, took about $2 \mathrm{~h}$ per participant.

\section{Results}

\section{Proportion of gamble choices}

As was expected, a positive, albeit moderate, correlation was found between financial literacy and numeracy, $r(98)=0.384, p<0.001, R^{2}=0.15$. As a first approach to exploring the impact of financial literacy and numeracy on performance in the experimental task, the proportion of gamble choices was subjected to a factorial repeatedmeasures ANCOVA including initial value, probability of retaining the entire initial amount (in the gamble option), framing of the sure option (keep or lose) and value difference between both options as repeated-measures factors, as well as numeracy and financial literacy as covariates. Focusing on the interactions between covariates (financial literacy and numeracy) and the repeated-measures variables, the following trends were ascertained: the formulation of the sure option (framing) interacted significantly with the degree of financial literacy, $F(1,97)=4.59, p=0.035$, partial $\eta^{2}=0.045$, but not with that of numeracy, $F<1$. In contrast, the value difference between the sure and gamble option interacted significantly with numeracy, $F(2,194)=10.23$, $p<0.001$, partial $\eta^{2}=0.095$, but not with financial literacy, $F<1$. As supplementary analyses, two more ANCOVAs were run, entering only the individual scores of financial literacy or of numeracy as covariates. In line with the previous outcomes, numeracy was found to interact significantly with the value difference between the two options, $F(2,196)=13.4, p<0.001$, partial $\eta^{2}=0.12$, but not with the framing of the sure option, $F<1$. On the other hand, financial literacy significantly interacted with the framing of the sure option, $F(1,98)=4.11, p=0.045$, partial $\eta^{2}=0.04$, but also with value differences, $F(2,196)=3.06, p=0.049$, partial $\eta^{2}=0.043$, most likely due to its significant correlation with numeracy. Taken altogether, these trends suggest a dissociation between financial literacy and numeracy, with the former moderating framing effects and the latter affecting sensitivity to expected values.

To scrutinise these effects more closely, participants were divided into subgroups of high and low financial literacy and numeracy, using as cut-off points the respective medians of the distribution of individual scores (19.5 for the Financial Literacy Questionnaire and 4.5 for the Abbreviated Numeracy Scale). Out of 100 participants, 26 were thus placed in the low financial literacy and low numeracy subgroup, 12 in the high financial literacy and low numeracy sub-group, 21 in the low financial literacy and high numeracy subgroup 
and 41 in the high financial literacy and high numeracy subgroup. The proportions of gamble choices were then subjected to a mixed ANOVA including initial value, probability of retaining the entire amount (the gamble option), framing of the sure option and value difference between options as repeated-measures variables, and numeracy (high/low) and financial literacy (high/low) as between-participants factors. Whenever the sphericity assumption was not met, a Greenhouse-Geisser correction for the degrees of freedom was performed.

Unsurprisingly, and overall, participants were found to be sensitive to value differences, choosing more frequently the option with the higher payoff, $F(1.79,172.05)=170.28$, $p=0.001$, partial $\eta^{2}=0.639$. However, they were also found to be more prone to choose the gamble option for lower initial values, $F(4.3,414)=4.72, p=0.001$, partial $\eta^{2}=0.047$, and for higher probabilities of retaining the entire amount, $F(1.54,147.89)=16.05, p<0.001$, partial $\eta^{2}=0.143$. Moreover, and of relevance, participants choose to gamble more often when the sure option was formulated in terms of the amount lost, $F(1,96)=21.96, p=0.001$, partial $\eta^{2}=0.186$, thus revealing a significant trend for risk propensity to avoid sure losses, in accordance with the framing effect. In addition, the probability of retaining the entire initial amount in the gamble option was found to interact significantly with the value difference between the two options, $F(4.28$, $410.7)=23.77, p<0.001$, partial $\eta^{2}=0.198$, with participants being less able to discriminate the differences in value between both options when there was a lower probability of retaining the entire initial amount in the gamble. Framing of the sure option was also found to significantly interact with the value difference between the two options, $F(2$, 192) $=5.112, p=0.007$, partial $\eta^{2}=0.051$, in a pattern in which the gamble option was more likely to be chosen when its expected value was equal to the sure option if formulated in terms of the amount lost. The framing effect, given by the higher likelihood of choosing the gamble option when paired with a sure option formulated in terms of losses, was also found to be amplified as the initial value increased, $F(4.47$, $429.77)=6.072, p<0.001$, partial $\eta^{2}=0.059$. Finally, the effect of the difference between the expected value in the gamble option and the value associated with the immediate sale (sure option) was slightly greater for smaller initial values, $F(10,960)=2.738, p=0.003$, partial $\eta^{2}=0.028$.

In line with the ANCOVA results, numeracy, $F(1.79$, $172.05)=5.026, p=0.01$, partial $\eta^{2}=0.05$, but not financial literacy, $F<1$, interacted significantly with the difference in value associated with the options. Participants with higher numeracy proved to be more sensitive to differences in value between options, choosing the gamble option more frequently when its expected value exceeded the value of the sure option and vice-versa (see Fig. 2; particularly the higher slopes of the lines in panels $\mathrm{C}$ and $\mathrm{D}$, when compared with panels A and B). On the other hand, financial literacy, $F(1$, 96) $=6.94, p=0.01$, partial $\eta^{2}=0.067$, but not numeracy, $F(1,96)=1.58, p=0.212$, was found to modulate framing effects. Participants with higher levels of financial literacy chose the gamble option more often when paired with an immediate sell option formulated in terms of the amount lost, compared with mathematically equivalent cases in which the sure option indicated the amount retained (see Fig. 2; particularly the vertical separation of the lines in panels B and D, when compared with panels A and C). No other interaction achieved the statistical significance level. However, a significant main effect was found for financial literacy, $F(1,96)=3.997, p=0.048$, partial $\eta^{2}=0.04$, but not for numeracy, $F<1$, with higher financial literate participants choosing the gamble option more often, across all conditions, in comparison with their less literate counterparts.

\section{Sensitivity to value and framing effects}

The analyses so far seem to suggest a dissociation between financial literacy and numeracy, with the former linked more closely to higher framing effects and the latter associated with higher sensitivity to value differences between both options. So as to isolated these trends, measures for both effects were devised and computed.

An Index of Normative Rationality was obtained, for each participant, by calculating the ration between the slope of the best linear fit between the proportion of gamble choices and the value differential (across all combinations of framing, probability and initial value) and the slope which would have been obtained for a respondent who consistently chose the option with the higher payoff. This measure thus varies between 0 (a pattern of choices which do not depend on the values associated with each option) and 1 (a pattern of responses which maximises the expected payoffs). As for the framing effects, a Framing Index was obtained by the difference in the proportion of gamble choices when the sure option was formulated in terms of losses and when formulated in terms of the amount retained (across all levels of value differential, probabilities and initial value). This measure thus reflects how much more likely a participant is to choose to gamble when faced with a sure option formulated in terms of losses (in comparison with retained amounts).

Figure 3 depicts the mean values obtained for the indexes of normative rationality (panel A) and framing (panel B) for the groups with high numeracy (white columns), low numeracy (grey columns), low financial literacy (columns on the left side) and high financial literacy (right-hand columns). In line with the previous analyses, it can be observed that irrespective of the level of financial literacy, the index of normative rationality tends to be higher for participants with higher levels of numeracy. Likewise, the framing index 


\section{Low Financial Literacy}
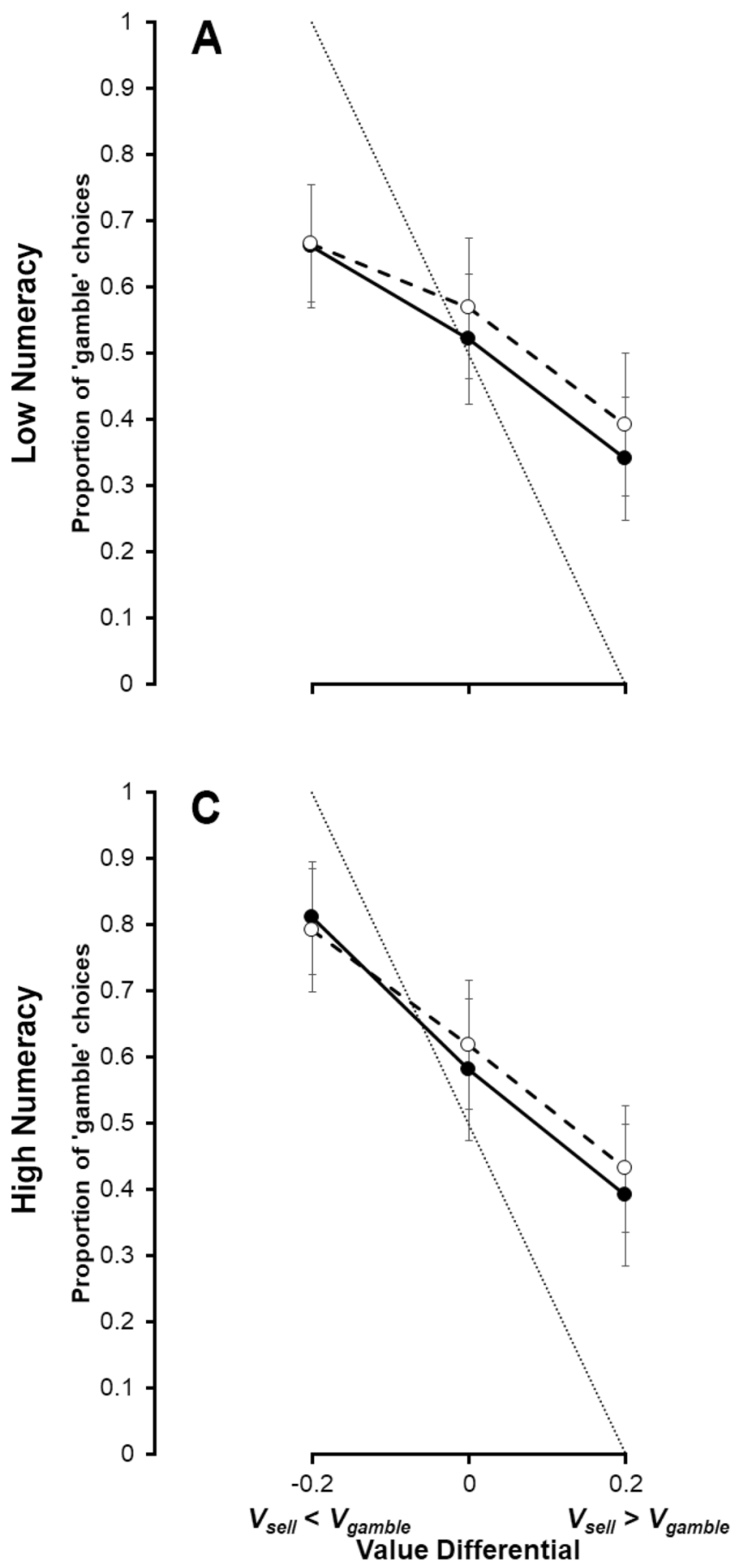

Fig. 2 Proportion of gamble choices as a function of the value differential between alternatives (gamble and sure option; abscissa), framing of the sure option (keep or lose a certain number of shares; line

increases for participants with higher financial literacy levels, regardless of their numeracy levels.

Statistical analysis supported visual inspection. The indexes of normative rationality and framing were entered

\section{High Financial Literacy}
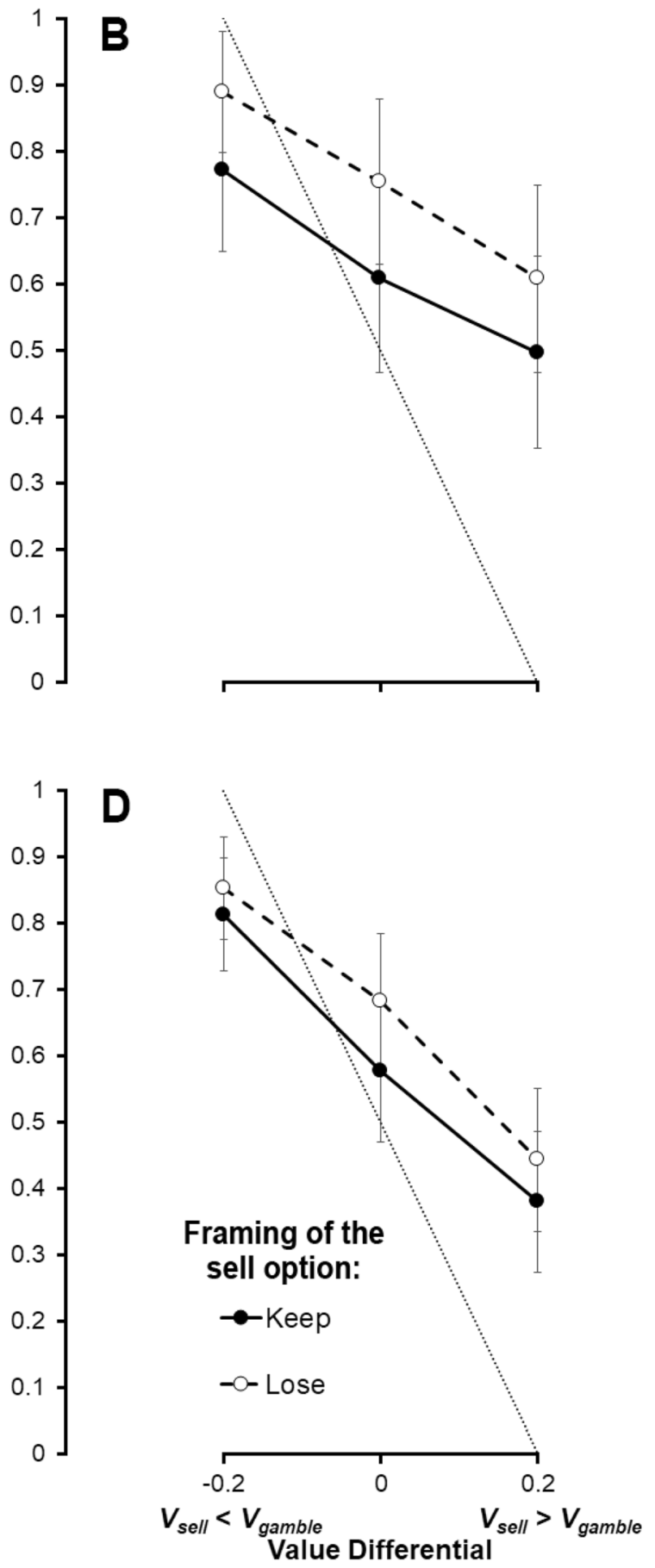

parameter), financial literacy (high/low; panel columns) and numeracy subgroups (high/low; panel rows). Vertical error bars depict the standard error of the means

as dependent variables in a MANOVA, with financial literacy and numeracy levels as between-participants factors. Numeracy, $F(1,96)=7.61, p=0.007$, partial $\eta^{2}=0.073$, but not financial literacy, $F<1$, significantly determined 


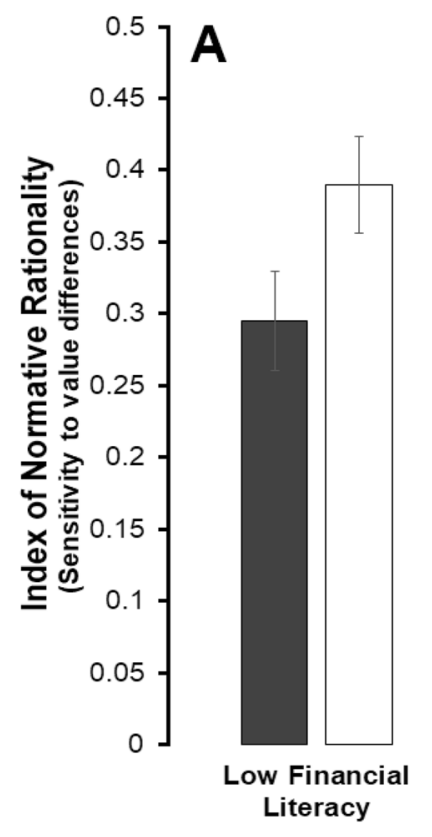

Fig. 3 Mean individual indexes of rationality (sensitivity to differences in value be-tween alternatives; a) and framing (differences in the proportion of choices of the gamble when the sure option was posed in terms of the amount lost or kept; b) for participants with

the index of normative rationality, with participants with higher numeracy more consistently choosing the option with higher payoffs, irrespective of their financial literacy levels, and as ascertained by a null interaction, $F<1$. The inverse pattern of results was found regarding the framing index, which significantly depended on financial literacy, $F(1$, $96)=6.941, p=0.01$, partial $\eta^{2}=0.067$, but not numeracy, $F(1,96)=1.58, p=0.212$. Overall, choices involving the gambling option were significantly affected by the formulation of the sure option and more so for those participants with higher levels of financial literacy, regardless of their numeracy levels, and as expressed by a null interaction outcome between both sets of expertise levels, $F<1$.

The outcomes strongly suggest that higher financial literacy far from immunising against framing effects might actually amplify them. On the contrary, higher levels of numeracy seem to enhance sensitivity to differences in value between the two options in such a way that numerate participants are more prone to choose the better-valued alternative more frequently. It could be argued that these outcomes result from the subdivision of the participants into subgroups. However, in opposition to such an interpretation and when considering the entire range of scores, individual framing indexes were found to be significantly correlated with individual financial literacy levels, $r(98)=0.201, p=0.045$, but not with the individual numeracy scores, $r(98)=0.011$, $p=0.912$. Moreover, the correlation remained significant when controlling for numeracy, $r(97)=0.213, p=0.035$.

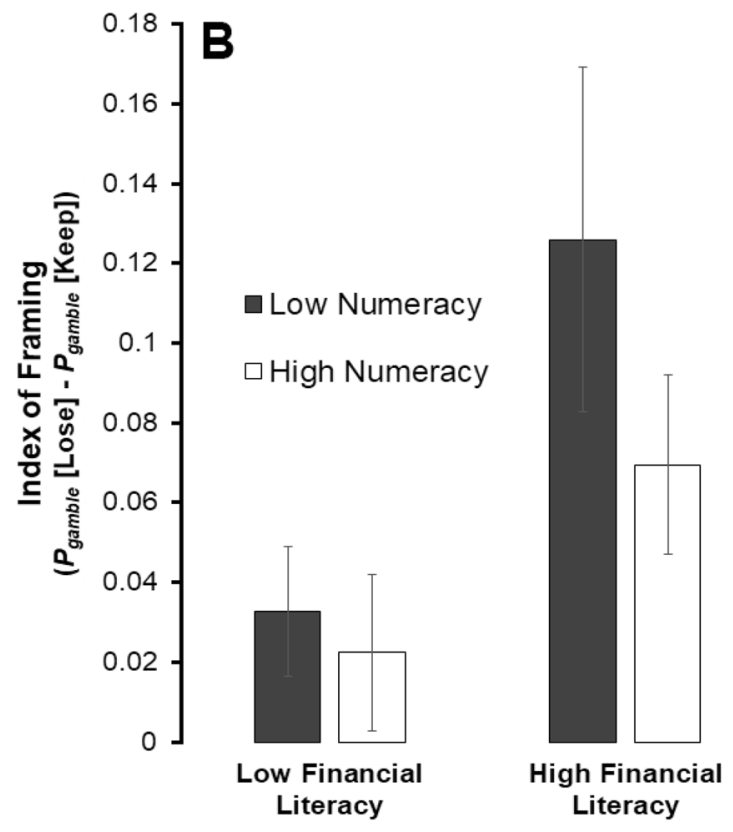

low (left columns in each panel) or high (right columns in each panel) financial literacy and low (grey columns) or high (white columns) numeracy. Vertical error bars depict the standard error of the means

Similarly, the individual indexes of normative rationality were found to be significantly correlated with the numeracy scores, $r(98)=0.42, p<0.001$, but also with financial literacy, $r(98)=0.211, p=0.035$. However, the latter correlation was found to be null when controlling for numeracy, $r(97)=0.059, p=0.561$.

\section{Discussion and conclusion}

This study aimed to ascertain the differential role of numeracy and financial literacy in decision-making under risk and uncertainty. Contrary to what would be expected, our results suggest that numeracy and financial literacy, taken as relevant sets of expert knowledge, underlie and moderate different response patterns-while numeracy seems to promote responses that conform to the normative model of rational choice, financial literacy chiefly magnifies susceptibility to framing effects.

Regarding numeracy skills, highly numerate participants were found to conform more closely with the normative standards of rationality, choosing the options with the higher expected payoffs more consistently, putatively implying the operation of deliberative cognitive processes. This result is in line with extant research showing that individuals with greater numeracy are more sensitive to numerical information and less influenced by non-numerical information, and thus more likely to conform to prescriptions of rational 
choice theory (Peters, 2012; Peters et al., 2006). Likewise, the found outcome is in line with dual-process approaches which emphasise a requirement for pre-existing relevant mindware for the emergence of Type 2 responses (Evans \& Stanovich, 2013; Stanovich et al., 2011, 2016).

Strikingly, financial literacy, which could also be taken as relevant mindware for the type of decisions involved in our task, not only failed to significantly affect the degree to which participants conformed to normative standards of rationality (e.g., the maximising of expected value), but was actually found to increase framing effects. That is, participants with higher levels of financial literacy were more prone to choose the gamble option when it was paired with a sure option formulated in terms of losses, in comparison with an equivalent problem formulated in terms of retained value, ceteris paribus. Since framing effects, defined as a change in response patterns for mathematically equivalent problems when posed in terms of gains or losses (as was the case in this study), are usually taken as a gross infraction of the invariance principle and thus disclosing the interference of intuitive-laden loss aversion in decision-making (Kanheman \& Frederick, 2007), our results would seem to suggest that financial literacy might actually amplify, rather than dampen, Type 1 responses and, by extension, to have a detrimental effect on financial decision-making. Within the scope of Prospect Theory, where framing effects are modulated as an asymmetric sensitivity to changes in expected utility, with losses being valued more heavily than gains, these results suggest that, in comparison with less financially literate participants, those with higher levels of financial literacy are particularly prone to take risks to avoid a sure loss (Kahneman \& Tversky, 1979).

The obtained outcomes, with financial literacy augmenting type 1 responses and decision biases, are unexpected and not entirely congruent with available research. While financial literacy has been reported to have, on average, no effect on financial decision making (see, e.g., Fernandes, Lynch, \& Netemeyer, 2014), to the best of our knowledge, the present study might be the first to actually suggest a detrimental effect of financial literacy. It could be argued that the absence of incentives might, at least partially, explain the results. Indeed, it is still a matter of contention the degree to which tangible rewards in decision tasks dampen or eliminate altogether commonly found bias and errors (cf. e.g., Hertwig \& Ortmann, 2001). Monetary payments seem to increase the amount of effort and attention and to eliminate careless errors, although not 'cognitive illusions' involved in reported departures from rationality (Arkes 1991; Camerer \& Hogarth, 1999; Grether \& Plot, 1979; Lichtenstein \& Slovic, 1973). In fact, these errors seem to persist even when sizable incentives are involved in the experimental ultimatum game (e.g., three times the monthly expenditure in Indonesia, cf. Cameron, 1999), or even in real world contexts, such as in stock investment (Barber \& Odean, 2000; Benartzi $\&$ Thaler, 2001). But even when granting the possibility that the absence of incentives explains the underperformance of the financially literate, by positing that lack of motivation led them to adopt the default (illiterate) path, it would leave unaccounted the difference with their lesser literate counterparts, i.e. that financial literacy heightens the framing effects. Relatedly, it is worth noticing that, since realworld financial decisions imply real payoffs and losses and, therefore, impact significantly on people's lives, it might also be argued that our results do not extend beyond the laboratorial setting. Without eschewing these concerns, it can as easily be argued that our results emerged not because our task involved hypothetical scenarios and merely virtual payoffs, but despite that very fact. Specifically, in referring to the higher susceptibility to framing effects for the highly financially literate participants, it would be hard to explain how such trends would emerge solely for a laboratory task and not in real-world financial settings (while the reverse would be plausible).

All things considered, we can, however, put forth a more sensible and plausible account for the found outcomes. By virtue of their greater familiarity with financial matters and risks associated with an investment in capital markets, it might be the case that the mental representations of the posed problems, for the highly financially literate individuals, more fully capture hypothetical financial aspects that are easily neglected by less financially literate individuals. That is, it might be argued that respondents with less financial knowledge, due to a lack of expertise in the financial domain, approached the posed scenarios merely as mathematical problems, not fully considering actual consequences, and were thus less susceptible to framing effects.

Be it as it may, our results do not support the assertion that financial literacy, in itself, provides an immunising effect for decision-making biases, in general, and framing effects, in particular. The outcomes serve to qualify efforts aimed at increasing financial knowledge among the general population. Albeit valuable and unquestionably useful, programmes aiming to foster financial literacy might not be effective in reducing decision-making biases, such as framing effects, not uncommonly pinpointed as relevant factors in explaining flawed financial behaviour (Chater, Huck, \& Inderst, 2010; Choi, Laibson \& Madrian, 2005; Thaler \& Sunstein, 2008). Notably, the same applies to numeracy which, although linked in our study with higher sensitivity to differences in expected value, proved to be unrelated to the degree to which participants fell prey to framing effects. As a matter of fact, and despite our replication of a significant correlation between the scores of financial literacy and numeracy (see also Skagerlund et al., 2018), this study also disclosed a dissociation between both sets of expert knowledge. While numeracy was found to significantly modulate 
sensitivity to differences in expected value between options, with more numerate participants choosing the option with the higher payoff more consistently, higher levels of financial literacy seemed to impact solely on the susceptibility to framing effects. Furthermore, we found no evidence for a significant interaction involving both patterns of responses, suggesting that the effects of numeracy and financial literacy are independent of each other and may act additively. As such, and insofar as a single individual may simultaneously possess both skills, he or she may be prone to display an increased sensitivity to the values of the available alternatives as well as an increased susceptibility to loss aversion.

Funding This work was supported by the Portuguese Foundation for Science and Technology (FCT) through a Doctoral Fellowship (SFRH/ BD/99484/2014) awarded to the first author.

\section{Compliance with ethical standards}

Conflict of interest The authors declare having no conflict of interest.

Ethical approval All procedures performed in studies involving human participants were in accordance with the ethical standards of the University of Coimbra and with the 1964 Helsinki Declaration and its later amendments or comparable ethical standards.

Informed consent Informed consent was obtained from all individual participants included in the study.

\section{References}

Arkes, H. R. (1991). Costs and benefits of judgment errors: Implications for debiasing. Psychological Bulletin, 110, 486-498.

Bank of Portugal. (2015). Survey on the Financial Literacy of the Portuguese Population. Lisbon: National Council of Financial Supervisors

Barber, B. M., \& Odean, T. (2000). Trading is hazardous to your wealth: The common stock investment performance of individual investors. The Journal of Finance, 55(2), 773-806.

Benartzi, S., \& Thaler, R. H. (2001). Naive diversification strategies in defined contribution saving plans. American Economic Review, 91(1), 79-98.

Camerer, C. F., \& Hogarth, R. M. (1999). The effect of financial incentives. Journal of Risk and Uncertainty, 19(1-3), 7-42.

Cameron, L. A. (1999). Raising the stakes in the ultimatum game: Experimental evidence from Indonesia. Economic Inquiry, 37(1), 47-59.

Cassotti, M., Habib, M., Poirel, N., Aïte, A., Houdé, O., \& Moutier, S. (2012). Positive emotional context eliminates the framing effect in decision-making. Emotion, 12(5), 926-931.

Chater, N., Huck, S., \& Inderst, R. (2010). Consumer decision-making in retail investment services: A behavioural economics perspective. Report to the European Commission Directorate-General Health and Consumers (SANCO), Brussels.

Choi, J., Laibson, D., \& Madrian, B. C. (2005). Are Empowerment and Education Enough? Under-diversification in 401(k) Plans. Brookings Papers on Economic Activity, 2, 151-198.
Cokely, E. T., \& Kelley, C. M. (2009). Cognitive abilities and superior decision making un-der risk: A protocol analysis and process model evaluation. Judgment and Decision-Making, 4, 20-33.

Crotty, J. (2009). Structural causes of the global financial crisis: A critical assessment of the new financial architecture. Cambridge Journal of Economics, 33, 563-580.

de Bassa Scheresberg, C. (2013). Financial literacy and financial behavior among young adults: Evidence and implications. Numeracy, $6(2), 5$.

De Martino, B., Kumaran, D., Seymour, B., \& Dolan, R. J. (2006). Frames, biases, and rational decision-making in the human brain. Science, 313, 684-687.

Diacon, S., \& Hasseldine, J. (2007). Framing effects and risk perception: The effect of prior performance presentation format on investment fund choice. Journal of Economy Psychology, 28, $31-52$.

Disney, R., \& Gathergood, J. (2013). Financial literacy and consumer credit portfolios. Journal of Banking \& Finance, 37(7), 2246-2254.

Epley, N., Mak, D., \& Idson, L. C. (2006). Bonus or rebate? The impact of income framing on spending and saving: Erratum. Journal of Behavioral Decision Making, 19(4), 407.

Evans, J. S., \& B. T., (2003). In two minds: Dual process accounts of reasoning. Trends in Cognitive Sciences, 7, 454-459.

Evans, J. S. B. T. (2010). Intuition and reasoning: A dual-process perspective. Psychological Inquiry, 21, 313-326.

Evans, J. S. B. T., \& Stanovich, K. E. (2013). Dual-process theories of higher cognition: Advancing the debate. Perspectives on Psychological Science, 8, 223-241.

Fernandes, D., Lynch, J. G., Jr., \& Netemeyer, R. G. (2014). Financial literacy, financial education, and downstream financial behaviors. Management Science, 60(8), 1861-1883.

Frederick, S. (2005). Cognitive reflection and decision making. Journal of Economic Perspectives, 19, 25-42.

Garcia-Retamero, R., Sobków, A., Petrova, D., Garrido, D., \& Traczyk, J. (2019). Numeracy and risk literacy: What have we learned so far? The Spanish Journal of Psychology, 22(e10), 1-11.

Grether, D. M., \& Plot, C. R. (1979). Economic theory of choice and the preference reversal phenomenon. American Economic Review, 69(4), 623-638.

Hertwig, R., \& Ortmann, A. (2001). Experimental practices in economics: A methodological challenge for psychologists? Behavioral and Brain Sciences, 24(3), 83-451.

Jappelli, T., \& Padula, M. (2013). Investment in financial literacy and saving decisions. Journal of Banking and Finance, 37(8), 2779-2792.

Kahneman, D., \& Frederick, S. (2007). Frames and brains: Elicitation and control of response tendencies. Trends in Cognitive Sciences, $11,45-46$.

Kahneman, D. (2003). Maps of bounded rationality: Psychology for behavioral economics. American Economic Review, 93(5), $1449-1475$

Kahneman, D. (2011). Thinking fast and slow. London: Penguin Books.

Kahneman, D., \& Frederick, S. (2002). Representativeness revisited: Attribute substitution in intuitive judgment. In D. Gilovich \& D. Kahneman (Eds.), Heuristics and biases: The psychology of intuitive judgment (pp. 49-81). New York: Cambridge University Press.

Kahneman, D., \& Tversky, A. (1979). Prospect theory: an analysis of decision under risk. Econometrica, 47(2), 263-262.

Kirsch, I., Kader, B., Jensen, G. V., \& Kopher, W. (2002). Adult Literacy in American US Department of Education. National Center for Education Statistics

Lichtenstein, S., \& Slovic, P. (1973). Response-induced reversals of preference in gambling: An extended replication in Las Vegas. Journal of Experimental Psychology, 101(1), 16-20. 
Lipkus, I. M., Samsaand, G., \& Rimer, B. K. (2001). General performance on a numeracy scale among highly educated samples. Medical Decision Making, 21, 37-44.

Lusardi, A. (2012). Numeracy financial literacy and financial decisionmaking. Numeracy, 5(1), 1-12.

Lusardi, A., \& Mitchell, O. S. (2007a). Baby boomer retirement security: The roles of planning, financial literacy and housing wealth. Journal of Monetary Economics, 54(1), 205-224.

Lusardi, A., \& Mitchell, O. S. (2007b). Financial literacy and retirement preparedness: Evidence and implications for financial education. Business Economics, 42(1), 35-44.

Lusardi, A., \& Mitchell, O. S. (2011). Financial Literacy and Retirement Planning in the United States. Journal of Pension Economics and Finance, 10(4), 509-525.

Lusardi, A., \& Mitchell, O. S. (2014). The economic importance of financial literacy. Journal of Economic Literature, 52(1), 5-44.

McNeil, B. J., Pauker, S. G., Sox, H. C., \& Tversky, A. (1982). On the elicitation of preferences for alternative therapies. New England Journal of Medicine, 306, 1259-1262.

Moore, D. (2003). Survey of Financial Literacy in Washington State: Knowledge, Behavior, Attitudes, and Experiences. Washington State University, Social and Economic Sciences Research Center: Technical Report 03-39.

O'Connell, A. (2008). Evaluating the effectiveness of financial education programmes. OECD Journal General Papers, 3, 9-51.

OECD. (2005). Improving financial literacy: analysis of issues and policies. Paris: OECD Publishing.

OECD. (2009). Financial literacy and consumer protection: overlooked aspects of the crisis. Paris: OECD Publishing.

OECD. (2017). G20/OECD INFE report on adult financial literacy in G20 COUNTRIES. Par-is: OECD Publishing.

OECD \& INFE. (2014). OECD/INFE progress report on financial education. Paris: OECD Publishing.

OECD \& INFE. (2016). International survey of adult financial literacy competencies. Paris: OECD Publishing.

Peirce, J. W. (2007). PsychoPy-Psychophysics software in Python. Journal of Neuroscience Methods, 162(1-2), 8-13.

Peirce, J. W. (2009). Generating stimuli for neuroscience using PsychoPy. Frontiers in Neuroinformatics, 2(10), 1-8.

Peters, E., \& Levin, I. P. (2008). Dissecting the risky-choice framing effect: Numeracy as an individual-difference factor in weighting risky and riskless options. Judgment and Decision Making, 3, 435-448.

Peters, E. (2012). Beyond comprehension: The role of numeracy in judgments and decisions. Psychological Science, 21(1), 31-35.

Peters, E., Slovic, P., Västfjäll, D., \& Mertz, C. K. (2008). Intuitive numbers guide decisions. Judgment and Decision Making, 3(8), 619-635.

Peters, E., Västfäll, D., Slovic, P., Mertz, C. K., Mazzocco, K., \& Dickert, S. (2006). Numeracy and decision making. Psychological Science, 17(5), 407-413.

Reyna, V. F., \& Brainerd, C. J. (2008). Numeracy, ratio bias, and denominator neglect in judgments of risk and probability. Learning and Individual Differences, 18, 89-107.

Sanford, A. J., Fay, N., Stewart, A., \& Moxey, L. (2002). Perspective in statements of quantity, with implications for consumer psychology. Psychological Science, 13(2), 130-134.
Santos, A. C. (2017). Cultivating the self-reliant and responsible individual: the material culture of financial literacy. New Political Economy, 22(4), 410-422.

Skagerlund, K., Lind, T., Strömbäck, C., Tinghög, G., \& Västfäll, D. (2018). Financial literacy and the role of numeracy: how individuals' attitude and affinity with numbers influence financial literacy. Journal of Behavioral and Experimental Economics, 74, 18-25.

Standard \& Poor's (2015). Financial Literacy around the World: Insights from the Standard \& Poor's Ratings Services. City: Global Financial Literacy Survey.

Stanovich, K. E., \& West, R. F. (1999). Discrepancies between normative and descriptive models of decision making and the understanding/acceptance principle. Cognitive Psychology, 38, 349-385.

Stanovich, K. E., \& West, R. F. (2000). Individual differences in reasoning: implications for the rationality debate. Behavioral and Brain Sciences, 23, 645-726.

Stanovich, K. E., West, R. F., \& Toplak, M. E. (2011). The complexity of developmental predictions from dual process models. Developmental Review, 31, 103-118.

Stanovich, K. E., West, R. F., \& Toplak, M. E. (2016). The rationality quotient $(R Q)$ : Toward a test of rational thinking. Cambridge: MIT Press.

Sutherland, R. (1992). Some unanswered questions on the teaching and learning of algebra. For the Learning of Mathematics, 11(3), 40-46.

Thaler, R. H., \& Sunstein, C. R. (2008). Nudge: Improving decisions about health, wealth, and happiness. New Haven: Yale University Press.

Tversky, A., \& Kahneman, D. (1981). The framing of decisions and the psychology of choice. Science, 211, 453-458.

Tversky, A., \& Kahneman, D. (1984). Choices, values, and frames. American Psychologist, 39(4), 341-350.

Tversky, A., \& Kahneman, D. (1986). Rational choice and the framing of decisions. Journal of Business, 59(4), 251-278.

Van Rooij, M., Lusardi, A., \& Alessie, R. (2011). Financial literacy and stock market participation. Journal of Finance Economics, 10(2), 449-472.

Von Neumann, J., \& Morgenstern, O. (1947). Theory of games and economic behavior (2nd ed.). Princeton: Princeton University Press.

Weller, J. A., Dieckmann, N. F., Tusler, M., Mertz, C. K., Burns, W. J., \& Peters, E. (2013). Development and testing of an abbreviated numeracy scale: A rasch analysis approach. Journal of Behavioral Decision Making, 26, 198-212.

Zokaityte, A. (2016). Financial literacy and numeracy of consumers and retail investors. Capital Markets Law Journal, 11(3), 405-413.

Publisher's Note Springer Nature remains neutral with regard to jurisdictional claims in published maps and institutional affiliations. 